\title{
Revista Brasileira de Enfermagem REBEn Transmissão vertical do HIV: situação
encontrada em uma maternidade de Teresina
}

Vertical transmission of HIV: situation found in a maternity of Teresina

Transmisión vertical del HIV: situación encontrada en una maternidade de Teresinai

Liliam Mendes de Araújo

Mestre em Ciências da Saúde. Universidade Federal do Piauí, Teresina, PI.

Endereço para Contato

Rua Senador Cândido Ferraz, 1645. CEP 64001-800. Teresina - PI. liliam.m.a@uol.com.br

Lídya Tolstenko Nogueira

Doutora em Enfermagem. Coordenadora do Programa de Mestrado em Ciências e Saúde. Centro de Ciências da Saúde. Universidade Federal do Piauí (UFPI). Teresina, $P I$.

Parte da dissertação de mestrado intitulada "Análise da implementação das ações/intervenções para prevenir a transmissão vertical do HIV em uma maternidad pública de Teresina-PI: recomendações e prática".

Submissão: $04 / 05 / 2007$

Aprovação: 06/07/2007

\section{RESUMO}

0 aumento dos casos de AIDS em mulheres evidencia um progressivo aumento da transmissão vertical do HIV, no Brasil e no Piauí. Considerando a relevância do tema o presente estudo teve como objetivo analisar as condições da implementação das normas e medidas recomendadas pelo Ministério da Saúde para prevenir a transmissão vertical do HIV em uma maternidade de Teresina - PI. O caminho teóricometodológico compreendeu o estudo da dinâmica organizacional e dos seus atores, por meio de abordagem qualitativa. Para obtenção dos dados foram realizadas 17 entrevistas semi-estruturadas. Os resultados mostraram que as recomendações do Ministério da Saúde não foram atendidas na sua totalidade evidenciando a precariedade da assistência prestada para o binômio mãe/filho.

Descritores: HIV; AIDS; Gestante.

\section{ABSTRACT}

The increase of the number of cases of AIDS among women reveals a progressive increase of the vertical transmission of HIV in Brazil, as well as in Piauí. Considering the relevance of the subject, this study had as objective to analyze the conditions of the implementation of the rules and measures recommended by the Ministry of Health to prevent the vertical transmission of HIV in maternity houses of Teresina-PI. The theoretical-methodological approach included the study of organizational dynamics and its actors, by means of qualitative approach. In order to obtain data, 17 semi-structured interviews were carried out. The results revealed that the recommendations of the Ministry of Health were totally followed, making more evident the weakness of the assistance provided, to the mother/son binomial. Descriptors: HIV, AIDS, Pregnant women.

\section{RESUMEN}

El aumento de los casos de AIDS en mujeres, evidencia un progresivo aumento de la transmisión vertical de lo HIV en el Brasil, e en el Piauí. Considerando la relevancia del tema, el presente estudio tuve como objetivo analizar las condiciones de la implementación de las reglas y medidas recomendadas por el Ministerio de la Salud para prevenir la transmisión vertical del HIV en una maternidad de Teresina-PI. El camino teórico-metodológico comprendió el estudio de la dinámica organizacional y de sus actores, a través del abordaje cualitativa.. Para la obtención de los datos fueran realizados 17 entrevistas medioestructuradas. Los resultados mostraran que las recomendaciones del Ministerio de la Salud non fueran atendidas en la suya totalidad, evidenciando la precariedad de la asistencia prestada, para el binomio madre / hijo.

Descriptores: HIV, AIDS, Mujeres embarazadas.

Araújo LM, Nogueira LT. Transmissão vertical do HIV: situação encontrada em uma maternidade de Teresina. Rev Bras Enferm 2007 jul-ago; 60(4):396-9.

\section{INTRODUÇÃO}

A transmissão vertical, também denominada materno-infantil, é a principal via de infecção pelo HIV em crianças. Estudos evidenciam que em cerca de $65 \%$ dos casos, a transmissão vertical do HIV ocorre durante o trabalho de parto e no parto, enquanto que a transmissão intra-útero corresponde a $35 \%$ e que 0 aleitamento materno aumenta o risco de transmissão vertical do HIV em torno de $7 \%$ a $22 \%{ }^{(1)}$.

Em 1994, os resultados do Protocolo 076 Pediatric Aids Clinical Trial Group (PACTG) demonstraram que o uso da zidovudina (AZT), reduzia a transmissão vertical do HIV em $67,5 \%$ quando administrada durante a gestação, trabalho de parto e parto e aos recém-nascidos que não foram amamentados. A taxa de transmissão no grupo sem intervenção quimioprofilática com AZT foi de $25,5 \%$, e de $8 \%$ no grupo que usou o AZT (2). Tais evidências levaram o Centro de Controle e Prevenção de Doenças (CDC) a 
recomendar o uso do AZT para mulheres HIV positivas durante o segundo $e$ terceiro trimestre de gestação e durante o parto, e para os seus neonatos, estendendo o tratamento até as seis primeiras semanas de vida (2).

Tendo como referência estudos científicos e a experiência de especialistas da área, o Ministério da Saúde publicou em 2003 o Consenso Nacional com as seguintes recomendações profiláticas para prevenção da transmissão vertical do HIV.

a) Oferecer teste anti-HIV, com aconselhamento pré e pós-teste, para todas as gestantes nos serviços de pré-natal, devendo a testagem ser sempre voluntária e confidencial;

b) Ministrar nas gestantes HIV + oAZT oral (a partir da $14^{\mathrm{a}}$ sem.); OAZT endovenoso nas parturientes, durante 0 trabalho de parto e parto até 0 clampeamento do cordão umbilical; e o AZT oral por seis semanas ao recémnascido (segundo diretrizes do Protocolo 076 do ACTG);

c) Escolher a via de parto de acordo com os critérios abaixo: a) recomendase parto por cesariana eletiva quando a carga viral e" 1000 cópias / ml ou desconhecida e idade gestacional e" 34 semanas. b) recomenda-se parto vaginal quando a carga viral for $<1000$ cópias / $\mathrm{ml}$ ou indetectável e idade gestacional e" 34 semanas;

d) Orientar a gestante/puérpera a substituição da amamentação com a introdução de leite artificial e outros alimentos, de acordo com a idade da criança, garantindo seu adequado crescimento e desenvolvimento ${ }^{(3)}$.

Em novembro de 2002, por meio da publicação da Portaria número 2 104/02, foi instituída mais uma recomendação para prevenir a transmissão vertical do HIV, a "oferta do teste rápido anti-HIV, com aconselhamento pré e pós-teste para todas as parturientes não aconselhadas e testadas durante 0 pré-natal, ou sem pré-natal, devendo a testagem ser igualmente sempre voluntária e confidencial" $(1,4)$

Entretanto, mesmo que estudos venham comprovando a redução da transmissão vertical do HIV e a despeito da disponibilidade de recursos terapêuticos capazes de reduzir a infecção no recém-nascido, esta continua representando um problema, entre outras causas, pela precariedade da organização dos serviços de saúde do país, no Nordeste e, em particular, no Piauí.

Desde a publicação do Protocolo 076 do ACTG, o Ministério da Saúde considera como prioridade a prevenção da transmissão vertical do HIV em virtude da continuidade de elevadas taxas no país, onde se observa que a transmissão vertical do HIV foi responsável por cerca de $94 \%$ dos casos em menores de 13 anos, no período de 1999/2000. Atualmente essa taxa é em torno de $83,6 \%(5,6)$.

O Ministério da Saúde estimou que em 2001 seriam diagnosticadas 202 gestantes HIV+ nos serviços de pré-natal e parto no Estado do Piauí, sendo que a cobertura no mesmo ano foi de apenas 2,5\%. ${ }^{\left({ }^{3}\right)}$ No município de Teresina, a maternidade responsável por $80 \%$ das consultas de pré-natal no ano de 2001, realizou testes anti-HIV em apenas $30 \%$ das gestantes atendidas. ${ }^{(7)}$ Embora o município de Teresina não represente a realidade do Estado como um todo, os dados disponíveis quanto ao número de testes realizados estão abaixo dos números apresentados em outros Estados do Brasil.

Em 2000, foram notificadas no Piauí 39 gestantes, sendo que em 71,7\% a notificação se deu a partir das crianças que eram acompanhadas na unidade de saúde de referência e 28,3\% nas maternidades. Em 2001, foram notificadas 14 gestantes e 13 crianças, $50 \%$ diagnosticadas no pré-natal, $42,8 \%$ em momento anterior à gravidez e $7,2 \%$ no momento do parto. Das 14 gestantes, 10 fizeram a quimioprofilaxia, segundo recomendações do Ministério da Saúde, enquanto que outras 4 gestantes, não realizaram. Quanto às crianças, naquele momento 9 estavam sendo acompanhadas e 5 estavam sem acompanhamento ${ }^{(7)}$.

Situação semelhante foi encontrada por Cavalcante ${ }^{(8)}$, ao analisar as condutas implementadas para prevenir a transmissão vertical do HIV no município de Fortaleza - Ceará, no período de 1999 a 2001, mostrando que das 138 gestantes infectadas pelo HIV, $35,5 \%$ souberam seu status sorológico antes da gestação, $48,6 \%$ durante a realização do pré-natal, $4,3 \%$ no momento do parto, e 11,6\% descobriram estar infectadas após o parto, ou por meio do diagnóstico na criança.

Segundo Neves et al(9), o percentual de oferta do teste nas Unidades Básicas de Saúde de Ribeirão Preto - SP atingiu no período de 1996 a 1998 índice de $68,3 \%$ das gestantes atendidas, resultando numa soropositividade de $0,76 \%$. Duarte et al ${ }^{(10)}$, no período de janeiro a junho do mesmo ano, em São João do Mereti - RJ, após analisar os registros em 2150 prontuários de parturientes, identificaram que apenas $19,76 \%$ das parturientes haviam realizado testes anti-HIV cujos resultados foram não reagentes, enquanto que em $80,24 \%$ dos prontuários das parturientes não continham informações acerca da testagem para HIV no pré-natal ou parto.

Todas as questões pontuadas até aqui demonstram que a implementação das medidas voltadas para a prevenção vertical do HIV e seu impacto é de difícil análise, principalmente pela ausência de dados relativos às ações realizadas no pré-natal. Entretanto, não se pode ignorar o papel das organizações de saúde, no que se refere à política institucional, condições tecnológicas, bem como o papel dos atores envolvidos no controle da transmissão vertical do HIV.

Face ao exposto, o objeto de estudo foi delimitado às ações/intervenções para prevenção da transmissão vertical do HIV realizadas em uma maternidade pública de Teresina, sob o ponto de vista da proposta política adotada pela instituição e dos discursos dos atores envolvidos. Para tanto o estudo teve como objetivos analisar as condições da implementação das normas e medidas recomendadas pelo Ministério da Saúde para prevenir a transmissão vertical do HIV.

\section{CAMINHO TEÓRICO METODOLÓGICO}

Este estudo voltou-se para a análise organizacional das condições de implementação de uma ação dirigida para prevenir a transmissão vertical do HIV, analisando a forma como as recomendações do Ministério da Saúde, voltadas para da transmissão vertical do HIV, são executadas no cotidiano organizacional. Nesse sentido a abordagem envolveu tanto as condições estruturais da organização, o funcionamento e o cotidiano da instituição em realizar a ação proposta, como também a percepção dos atores envolvidos.

A pesquisa foi desenvolvida em Teresina, capital do Piauí, atualmente com cerca de 714.318 mil habitantes, em uma maternidade pública, escolhida em razão dos seguintes critérios: ser a de maior porte e responder por $60 \%$ dos atendimentos obstétricos no município; ser unidade de referência para o Estado, bem como para Estados vizinhos; apresentar fluxo permanente de gestantes e parturientes assistidas garantindo uma diversidade significativa de mulheres; contar com uma equipe multiprofissional, que realiza atendimento ao pré-natal e ao parto ${ }^{(11)}$.

Os sujeitos da pesquisa foram 17 profissionais de saúde, dos quais, sete enfermeiras e 10 médicos, que trabalhavam no serviço de pré-natal, e/ou parto e a saturação dos discursos foi o referencial utilizado para o encerramento da etapa de obtenção de dados.

Para obter informações sobre o papel dos sujeitos sociais frente às proposições de mudanças com a implementação das ações recomendadas pelo Ministério da Saúde, recorreu-se a entrevista semi-estruturada, que permite ao entrevistado desenvolver suas opiniões e informações da maneira que for mais conveniente, ficando o entrevistador no papel de orientador $e$ estimulador. As entrevistas tiveram duração média de trinta minutos, e foram gravadas ante a explicitação dos seus objetivos, em data, horário e local de conveniência dos sujeitos e mediante assinatura do Termo de Consentimento Livre Esclarecido, conforme recomendação da Resolução 196/96 do Conselho Nacional de Saúde. Posteriormente, as entrevistas foram transcritas pela pesquisadora e devolvidas para os entrevistados para leitura dos discursos.

A organização dos dados foi realizada de acordo com Minayo ${ }^{(12)}$, que apresenta os seguintes passos: ordenação dos dados, a partir da transcrição 
imediata das gravações, com posterior leitura e releitura do material e organização dos relatos; classificação dos dados, por meio de leitura exaustiva de todo conteúdo para assimilação das idéias centrais, bem como identificação das categorias, originadas dos relatos.

Para analisar os discursos, foram utilizadas como referência as normas técnicas do Ministério da Saúde, permitindo relacionar a situação ideal com os fatos reais, considerando os limites e as possibilidades. Estudos ${ }^{(13,14)}$ possibilitaram a compreensão das estruturas fundamentais para implantação das ações para prevenir a transmissão vertical do HIV.

\section{RESULTADOS E DISCUSSÃO}

O termo "resultados" é utilizado para indicar uma ligação entre o estado atual e futuro da saúde do paciente. A melhora da saúde do paciente é 0 principal objetivo a ser alcançado, e o tipo da assistência prestada é considerada fundamental para obtenção de resultados satisfatório ${ }^{(14)}$.

Desta forma, os resultados mostraram as condições em que as gestantes, parturientes e crianças expostas ao HIV estavam sendo assistidas na instituição em estudo e, ao mesmo tempo, demonstram que a implementação de diretrizes que caracterizam mudanças no modelo assistencial, quanto aos procedimentos técnicos ou administrativos e que visem a alteração no modo da produção de serviços de saúde, torna-se um componente importante para reestruturação do setor saúde.

Quando questionados a respeito das medidas implementadas na instituição para prevenir a transmissão vertical do HIV, os entrevistados foram enfáticos em apontar a solicitação do teste anti-HIV no pré-natal, conforme mostra o discurso abaixo:

Faz parte da rotina de pré-natal a solicitação do teste anti-HIV de todas as gestantes, mesmo sendo um teste voluntário nós estamos fazendo em praticamente $100 \%$ das pacientes, porque não existe recusa em fazer o teste. (D4)

Foi observado que, de acordo com o depoimento, a instituição em estudo segue as orientações estabelecidas pelo Ministério da Saúde, quanto à oferta do teste anti-HIV para todas as gestantes nos serviços de pré-natal. Entretanto, ao comparar o número de consultas realizadas no primeiro trimestre, com 0 número de amostras enviadas ao Laboratório Central (LACEN), constatouse que os discursos dos atores responsáveis pela realização da ação são discordantes dos dados encontrados. No ano de 2003 foi realizada uma média mensal de 1.235 consultas de pré-natal em gestantes no primeiro trimestre, a média de exames anti-HIV foi de 400 exames mês, indicando uma cobertura de apenas $32,4 \%$.

Dessa forma, é importante enfatizar o pensamento de Hartz ${ }^{(13)}$ quando afirma que a "implantação de uma intervenção pode se revelar difíci principalmente se ela exigir modificações importantes nas práticas habituais dos agentes de implantação". Assim, a despeito de ter sido incorporada nos discursos dos profissionais a importância da oferta do exame anti-HIV no pré-natal, a baixa cobertura de gestantes testadas evidencia que a prática não está produzindo o efeito esperado.

Outro dado que chamou atenção foi o número de testes rápidos anti-HIV realizados na instituição pesquisada. O Ministério da Saúde, em 2001, estimou que aproximadamente 160 parturientes chegariam todos os meses ao serviço sem terem sido aconselhadas e testadas para o diagnóstico do HIV, demandando o aporte de 200 testes rápidos para uso em situação de prevenção da transmissão vertical do HIV('). Como no ano de 2003 foram realizados 166 testes rápidos anti-HIV ${ }^{(7)}$ é possível afirmar que a maternidade não alcançou a estimativa mensal e que algumas parturientes HIV+ podem não

a Os dados referentes ao número de consultas no $1^{\circ}$ trimestre foram obtidos no setor de estatistica da instituição, os dados sobre os testes anti-HIV, no laboratório do serviço pré-natal, e posteriormente confirmados pelo LACEN. ter sido diagnosticadas

A baixa cobertura na realização dos testes rápidos anti-HIV pode ser explicada pelos depoimentos que seguem:

No que diz respeito à disponibilidade do material para realização do teste rápido anti-HIV, nós já tivemos alguns momentos sem esse material. Recentemente nós passamos por um período relativamente longo, eu creio que uns dois meses aproximadamente sem o material e conseqüentemente sem realizar o teste. Esse é um problema que temos não só de hoje, já passamos por essa situação não só uma vez. (D8)

Quando a enfermeira não está presente, mesmo tendo material, o teste não é realizado. (D9)

$O$ depoimento do entrevistado $n^{0} 9$ sinaliza pontos importantes para reflexão, dentre os quais considera-se de grande importância o fato de os profissionais médicos julgarem a realização do teste rápido como uma atribuição da equipe de enfermagem, conseqüentemente levando, muitas vezes, a não identificação de possíveis casos de parturientes HIV+.

Contudo, considerando a forma como os serviços de saúde estão organizados, admite-se que os modelos desenvolvidos, associados muitas vezes ao despreparo dos profissionais, dificultam a assistência integral à mulher. Para Pinheiro et a ${ }^{(15)}$, a integralidade pode ser facilmente entendida como uma assistência além da aplicação das técnicas de prevenção, como atendimento de outras necessidades que não as diretamente ligadas à doença presente ou que pode vir a se apresentar, como a simples necessidade da conversa. Assim, a prática profissional e a organização do trabalho de uma equipe podem ser algo fundamental para garantir a integralidade da assistência.

Nesta perspectiva, deve-se considerar a realização do teste anti-HIV no pré-natal, e a oferta do teste rápido para parturientes, como instrumentos que possibilitarão a reflexão e uma tomada de decisão conjunta acerca das medidas protetoras.

A indisponibilidade do inibidor de lactação (Cabergolina 0,5 mg), também foi mencionado como uma dificuldade, conforme os relatos abaixo:

\section{Muitas vezes nós já ficamos sem o inibidor de lactação. (D16)}

A inibição da lactação não esta sendo feita de rotina, por não ter o material aqui na maternidade, mas já esta sendo providenciado. (D5)

É importante enfatizar que o inibidor é fornecido mediante solicitação formal à farmácia de referência, obedecendo a mesma rotina de aquisição do anti-retroviral e que a Portaria $n^{\circ} 822 / \mathrm{GM}$ assegura o pagamento do inibidor, quando adquirido pela instituição.

Segundo as recomendações do Ministério da Saúde, ao se inibir a lactação, deve-se oferecer alimentação artificial ao recém-nascido. Em relação a este ponto, nenhuma outra dificuldade relatada pelos entrevistados o foi com tanto inconformismo e indignação quanto a falta da fórmula láctea ou fórmula infantil. Os dois discursos que seguem retratam esses sentimentos.

A mãe não pode amamentar e não temos o leite para oferecer. Então você implanta o serviço, tem a medicação, a mãe tem direito ao leite e você não sabe o que fazer, porque ela vai parar ali, e vai amamentar, pois não tem o dinheiro para comprar. (D2)

Muitas vezes realizamos todos os procedimentos, e na hora da alta não tem o leite. O menino com fome, se a mãe não tinha o leite artificial, é quase certeza absoluta que ela tenha dado o peito. Nós não sabemos o que aconteceu... Por que não se faz um acompanhamento após a alta. (D4)

Vencidas as barreiras impeditivas à identificação das gestantes/parturientes 
$\mathrm{HIV}+$, a oferta do AZT desde o pré-natal até o nascimento da criança, o trabalho de prevenção da transmissão vertical se torna ameaçado pela ausência da fórmula láctea, justificando a reação dos entrevistados. O substituto do leite materno deve ser considerado, neste caso, como um alimento e medicamento. Os autores enfatizam a importância do aconselhamento e da necessidade do serviço estar organizado para oferecê-lo(16).

A falta dos insumos necessários para realização das ações evidencia a precariedade da assistência e os improvisos cotidianos a que estão submetidos as gestantes/parturientes e crianças expostas ao HIV e os profissionais de saúde. A falta de apoio institucional é apontada como um dos fatores contribuintes para essa situação, conforme explicitado no discurso que será analisado a seguir:

Acho que deveria ter um engajamento maior da instituição na implantação das ações para prevenir a transmissão vertical do HIV, o que houve na verdade foi uma iniciativa de um pequeno grupo de profissionais, que procurou a diretoria para forçar a implantação do Projeto Nascer, e eu acho que deveria ter sido o contrário, a diretoria era quem deveria cobrar a realização das ações. (D5)

Esta situação reflete a complexidade da organização de saúde, particularmente quando o processo de mudança requer o envolvimento dos diferentes atores e interesses institucionais. A implantação e a eficácia de uma intervenção dependem dos interesses particulares dos atores influentes na organização, em que a adoção e a implantação de novas intervenções são consideradas como jogos de poder organizacional. Dessa forma a organização é considerada uma arena política no interior da qual os atores envolvidos perseguem estratégias diferentes ${ }^{(13)}$. Portanto, para o cumprimento dos pressupostos éticos assumidos pela instituição, o envolvimento dos atores sociais torna-se imprescindivel.

O modelo assistencial proposto pelo SUS ainda não é uma realidade, e o gerenciamento do setor saúde vem se mostrando precário, em face ao pouco preparo da maioria dos gestores, o que, sem dúvida, é agravado pela crise econômica do país, que conseqüentemente gera mais demanda nos serviços ${ }^{(17)}$
Uma boa estrutura envolve recursos suficientes e um desenho de sistema apropriado é, provavelmente, o meio mais importante de proteger e promover a qualidade da atenção. Entende-se com isso que medidas corretivas, visando melhorar a estrutura organizacional, são necessárias para se obter os resultados esperados ${ }^{(14)}$.

\section{CONSIDERAÇÕES FINAIS}

As recomendações das normas e medidas para prevenir a transmissão vertical do HIV, como parte da política de saúde do país, culminando com os princípios doutrinários do SUS, demonstra, neste estudo, que apesar da normatização existente, com clara definição do papel das organizações de saúde na adoção dessas ações, o processo de institucionalização no âmbito organizacional mostra-se mais limitado e atrelado à vontade pessoal de uma parcela pequena de profissionais do que em mudanças efetivas verificadas no âmbito institucional, sem valorizar a estrutura necessária e o envolvimento das pessoas.

As oportunidades perdidas para realizar a intervenção preventiva, quer no pré-natal, parto e para o recém-nascido, mostram a debilidade organizacional e a pouca importância dada ao controle da transmissão vertical do HIV pelos profissionais, sejam eles gerentes ou não, demonstrado, principalmente, pelo distanciamento existente entre as normas e medidas recomendadas e a realidade encontrada.

Entretanto, diante dos achados, é importante enfatizar que para o cumprimento dos pressupostos éticos assumidos pela instituição, é necessário maior envolvimento dos profissionais na elaboração do Plano de Ações e Metas de DST/AIDS do Estado, direcionadas não apenas a gestantes, parturientes e crianças expostas ao HIV, mas para mulheres em idade reprodutiva, tendo em vista a importância de oferecer oportunidade de identificação precoce do vírus, mesmo antes da gestação.

Os resultados encontrados neste estudo permitiram concluir que a integração dos vários setores responsáveis pela realização das ações, caracterizando a intersetorialidade, são fundamentalmente importantes para que se possa assegurar assistência de forma integral, principalmente para 0 binômio mãe/filho.

\section{REFERÊNCIAS}

1. Ministério da Saúde (BR). Coordenação Nacional de DST/AIDS Guia de Tratamento: recomendações para profilaxia da transmissão materno-infantil do HIV e terapia anti-retroviral em gestantes, 2002/2003. Brasília (DF); 2003.

2. Centers for Disease Control and Prevention - CDC Recommendations of the U.S. public health service task force on the use of zidovudina to reduce perinatal transmission of human immunodeficiency virus. MMWR 1994; 43(RR- 11).

3. Ministério da Saúde (BR). Programa Nacional de DST/AIDS Manual de treinamento: projeto nascer. Brasilia (DF); 2003.

4. Ministério da Saúde (BR). Portaria Técnica Ministerial no 2104 / GM, de 19 de novembro de 2002. Diário Oficial da União 2002 21 nov.

5. Ministério da Saúde (BR). Coordenação Nacional de DST/AIDS. Boletim Epidemiológico da AIDS. Brasília (DF); 2000. 8(1): 5-6.

6. Ministério da Saúde (BR). Programa Nacional de DST/AIDS Boletim Epidemiológico da AIDS. Brasilia (DF); 2004. 15(1): 5-6.

7. Secretaria de Saúde do Estado (PI). Coordenação Estadual de DST/AIDS. Relatório da vigilância epidemiológica das DST/AIDS e sifilis congênita. Teresina (PI); 2002.

8. Cavalcante MS. Identificação das gestantes infectadas pelo HIV e análise das condutas utilizadas na prevenção da transmissão vertical do Vírus da Imunodeficiência Humana (HIV) em FortalezaCeará no período de 1999 a 2001 (dissertação). Fortaleza (CE) Universidade Federal do Ceará, Fortaleza; 2003.
9. Neves FRAL, Passos ADC, Gueleri WL. Disponibilidade de sorologia anti-HIV como teste voluntário na rotina do atendimento pré-natal em unidades básicas de saúde. Rev Saúde Pública 1999 dez;33(6):624-5.

10. Duarte AP, Sousa TML, Nascimento RA, Leite FH, Araujo SS, Jesus MS, et al. Qualidade do pré-natal no tocante a doenças sexualmente transmissíveis. J Bras DST 2002;14(3):34-115.

11. Prefeitura Municipal de Teresina/Fundação Municipal de Saúde. Relatório de Gestão 2002. Teresina (PI): Fundação Municipal de Saúde; 2003.

12. Minayo MCS. Pesquisa social: teoria, método e criatividade. $21^{a}$ edição. Petrópolis (RJ): Vozes; 2002.

13. Hartz ZMA. Avaliação em saúde: dos modelos conceituais à prática na análise da implantação de programas. Rio de Janeiro (RJ): Fiocruz; 1997.

14. Donabedian A. La calidad de la atención médica: definición y métodos de avaluación. Cuidad de México (MEX): Ediciones Copilco S.A; 1984.

15. Pinheiro R, Mattos R. Os sentidos da integralidade na atenção e no cuidado à saúde. Rio de janeiro (RJ): ABRASCO; 2001.

16. Matida LH, Oliveira CAF, Machado DM, Cruz EF, Milanez HMBPM, Marques HHS, et al. A supressão do aleitamento materno e o HIV. J Bras AIDS 2003;4(2):67-71.

17. Zardo VTN. Avaliação da assistência à gestante: uma análise localizada (dissertação). Ponta Grossa (PR): Universidade Federal de Ponta Grossa; 2000. 